\title{
THICKNESS DIFFERENCE OF THE LITHOSPHERE AT THE FRACTURE ZONE AND HORIZONTAL DRIVING FORCE OF THE PLATE
}

\author{
Yoshibumi Tomoda, Hiromi Fujimoto, and Takeshi Matsumoto \\ Ocean Research Institute, the University of Tokyo, Tokyo, Japan \\ (Received May 27, 1983; Revised October 29, 1983)
}

\begin{abstract}
Gravity anomalies and crustal structures are summarized in the vicinity of Mendocino Fracture Zone, and the thickness of the lithosphere is calculated from this information. The lithosphere south of the fracture zone is a few tens of kilometers thicker than that north of it, therefore the fracture zone is the place of the offset of lithospheric structure. This suggests the existence of horizontal pressure difference and the possibility of new subduction motion at the fracture zone.
\end{abstract}

\section{Introduction}

The Mendocino Fracture Zone is an extension of the transform fault which intersects the ridge axis dividing the North American Plate from the Pacific Plate.

The gigantic fracture zone, extending west more than $5,000 \mathrm{~km}$, has attracted the attention of many investigators, and many observations and interpretations have been made.

Trial observations were made whenever new techniques, such as magnetic measurement at sea, sea gravimetry, explosion seismology, and heat-flow measurement, were developed. This region is also where geomagnetic lineations which became the basis of the theory of plate tectonics were precisely determined.

The region is characterized by the fact that most kinds of geophysical data have been collected there, and these results are summarized in Vol. 4 of "The Sea" (DEHLINGER et al., 1970). Recently, the deep structure of the region has been interpreted using the undulation of geoid obtained from satellite altimeter data (DÉTRICK, 1981).

In this paper, the authors have tried to investigate the thickness anomaly of the region's lithosphere by using both the results of gravimetry and those of crustal structure determined by explosion seismology-Yoshii's Residual Gravity Anomaly (YosHIr, 1973).

So far, we have determined the global thickness anomaly of lithosphere in the Pacific, and also determined the local thickness anomaly of lithosphere for several interesting regions such as trenches, seamounts and oceanic plateaus.

Examples obtained for the Japan Trench, Hawaiian Ridge and Shatsky Rise are summarized in Fig. 1 (TomodA and Fusmoto, 1981; TOMODA et al., 1982). 


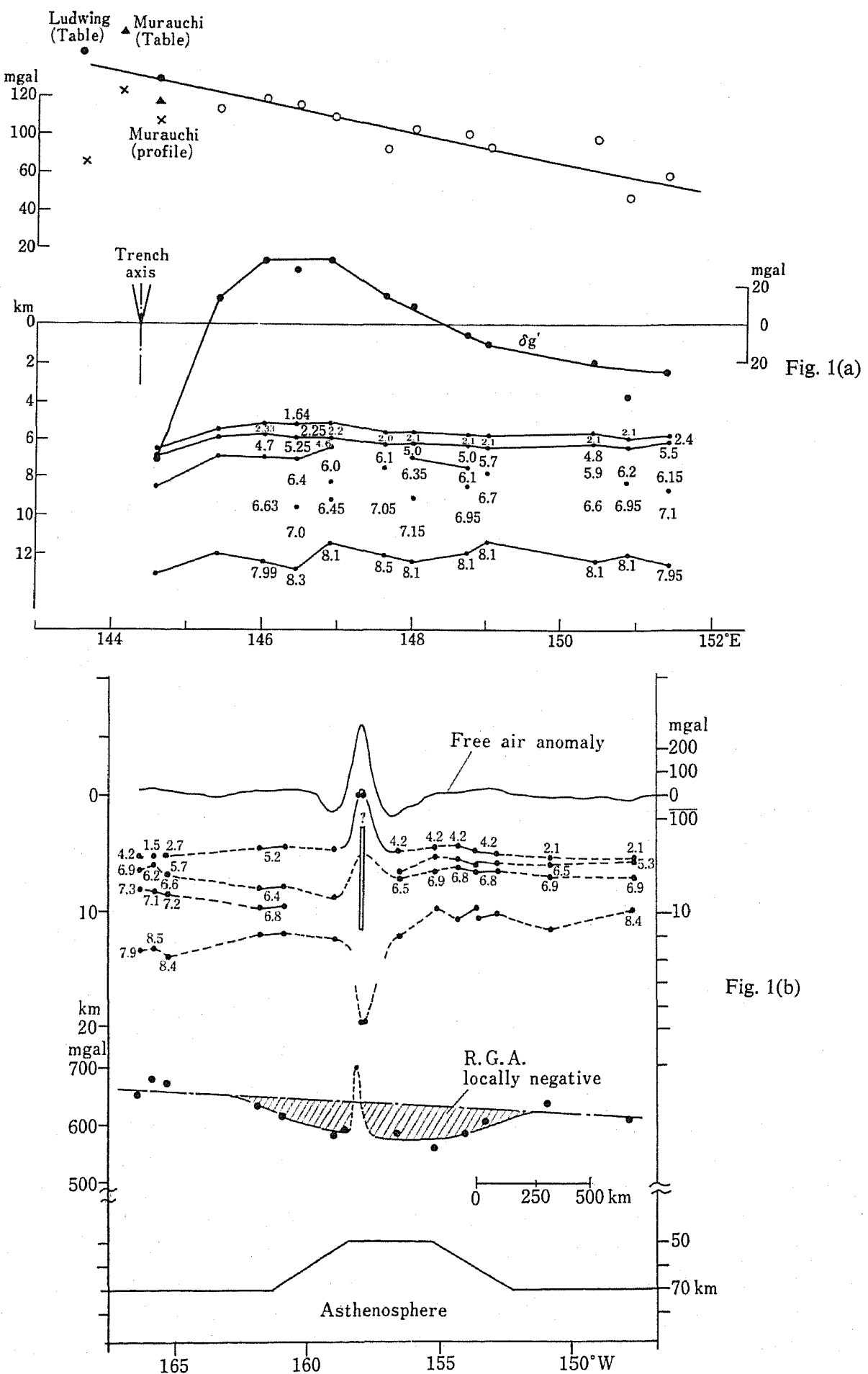




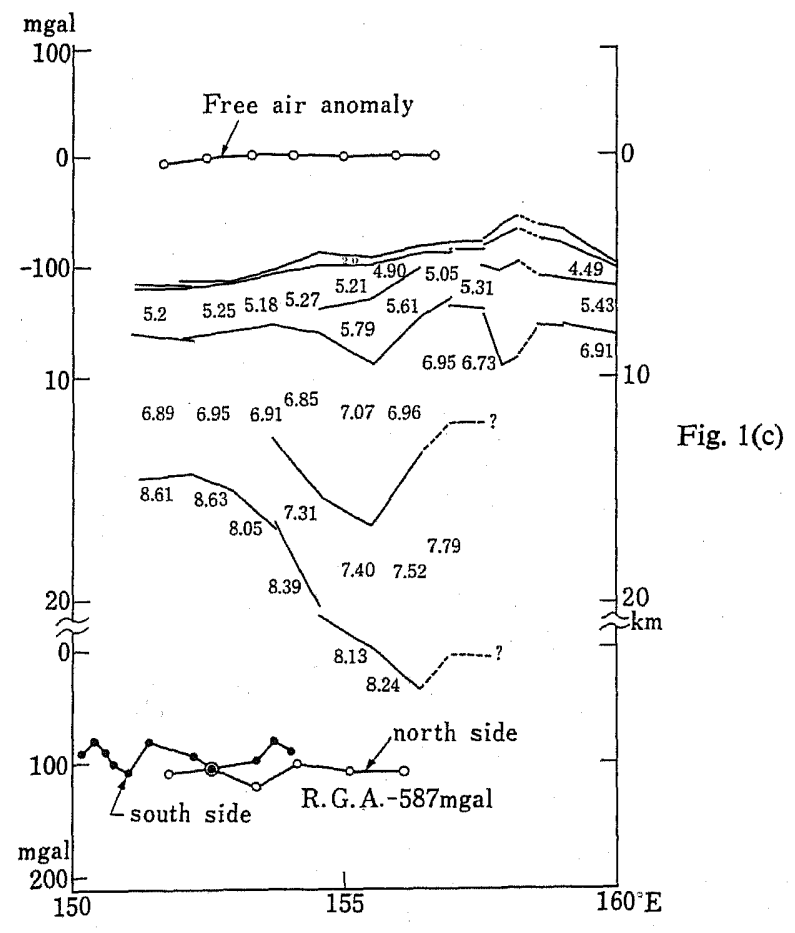

Fig. 1. Profiles of free air anomaly, crustal structure and R.G.A. (a) Japan Trench along $39^{\circ} \mathrm{N}$. (b) Hawaiian Ridge across Oahu Island. (c) Shatsky Rise along $32^{\circ} \mathrm{N}$.

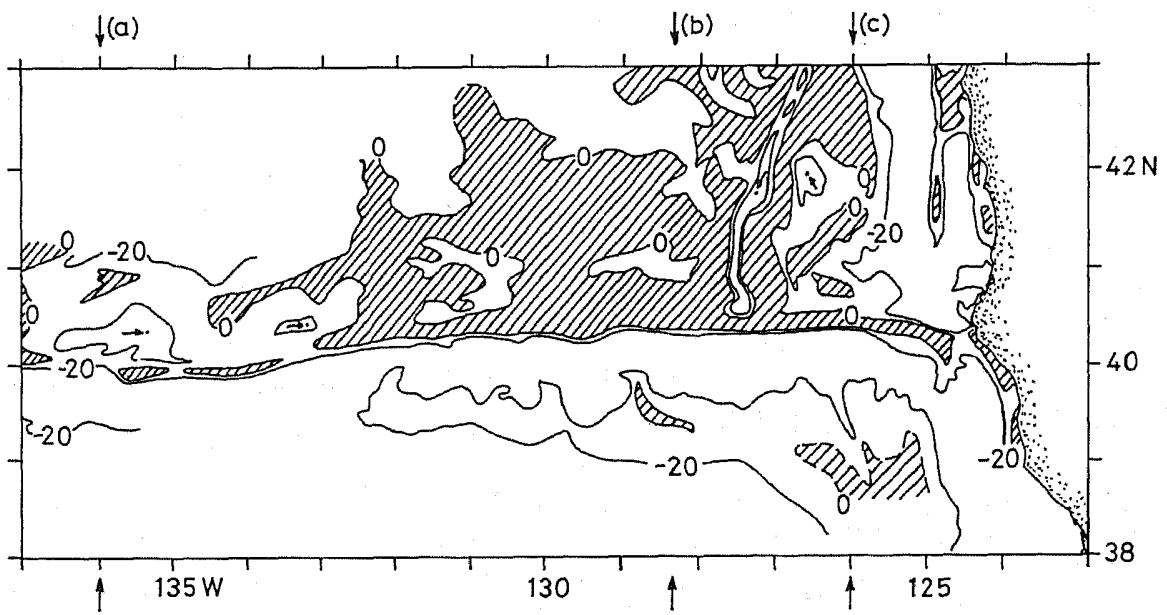

Fig. 2. Simplified map of free air anomaly modified after DeHLINGER et al. (1967). Hatched area shows positive. (a), (b), and (c) indicate the location of profile (a), (b), (c) in Fig. 4, respectively. 
1) East of the Japan Trench, the thickness of the lithosphere becomes gradually thicker from about $1,000 \mathrm{~km}$ seaward of the trench.

2) In the Hawaiian Ridge, thickness of the lithosphere beneath the ridge is about $20-30 \mathrm{~km}$ thinner with a horizontal extent of about $500 \mathrm{~km}$.

3) In Shatsky Rise, the thickness of the lithosphere is almost constant, though the crust is about $30 \mathrm{~km}$ thicker beneath the rise than the surrounding crust.

The thickness of the lithosphere is important for considering the force acting on the lithosphere. For example, thick lithosphere near the trench accelerates the subduction by its negative buoyancy, mass excess at the seamount chain is supported by the buoyancy of thin lithosphere, and some types of ridge or rise effect the motion of the lithosphere little, because the topography is in perfectly equilibrium condition.

How great then, is the difference in thickness of the lithosphere in the northern and southern regions of the Mendocino Fracture Zone, and what kind of geophysical process can be expected with this difference in lithosphere thickness?

\section{Gravity Anomaly near the Mendocino Fracture Zone}

Detailed gravity surveys have been carried out in the region, and gravity anomalies distributing have been given (DeHLINGER et al., 1967). Figure 2, a simplified map of free-air anomalies, shows that free-air anomalies negatively larger than $-20 \mathrm{mgal}$ extend wider than $200 \mathrm{~km}$ to the south of the fracture zone. Considering the wavelength of the gravity anomalies, it is clear that the isostasy is not achieved by the structure shallower than the Moho surface.

\section{Results of Explosion Seismology}

In the north and south regions of the Mendocino Fracture Zone, velocity structure above the Moho was determined by explosion seismology (RAITT, 1963; SHOR et al., 1968). One of the main characteristics in the velocity structure is that the water depth in the southern region is greater than that in the northern region by more than $1,000 \mathrm{~m}$, and that the southern crust is $4 \mathrm{~km}$ thicker.

The information included in geoid and free-air anomaly is the same, and therefore the same deep crustal structure will be obtained using geoid determined by satellite altimetry (DETRICK, 1981).

\section{Residual Gravity Anomaly}

By use of gravity anomaly and velocity structure obtained so far, "Residual Gravity Anomaly" is computed according to the method which we have applied to the Pacific.

Thickness of the lithosphere is also calculated based on the assumption that 


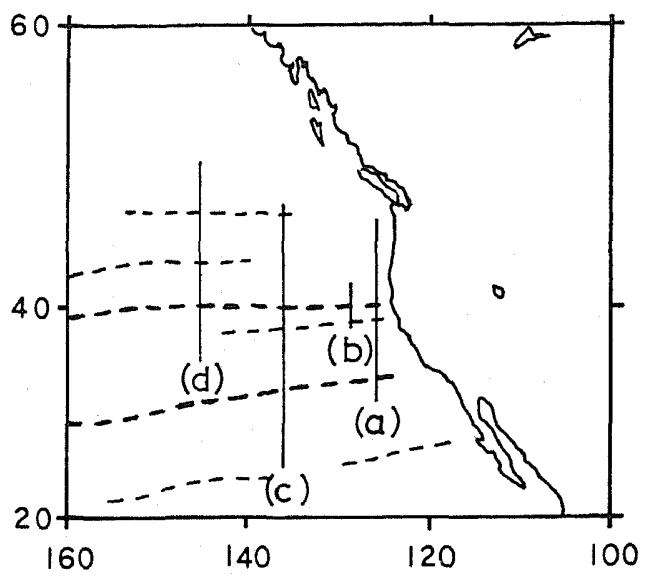

Fig. 3. Location of the cross sections of geophysical data shown in Fig. 4.

the densities of the lithosphere and asthenosphere are $3.3 \mathrm{~g} / \mathrm{cm}^{3}$ (density corresponding to the layer of $P$-wave velocity of $8.1 \mathrm{~km} / \mathrm{sec}$ ) and $3.2 \mathrm{~g} / \mathrm{cm}^{3}$, respectively.

The profiles across the fracture zone are made along the four lines shown in Fig. 3, and the results are shown in Figs. 4(a)-4(d), in which closed circles show the positions where the velocity structure is given and the residual gravity anomaly is calculated. In these figures, the thickness of the lithosphere is given assuming that it is proportional to R.G.A., as usually assumed in calculating the thickness of the crust from the simple Bouguer anomaly.

In order to determine the detailed shape of the lithosphere across the fracture zone, the profile 4(b) was selected, and two dimensional analysis was carried out. The thickness difference due to the difference of age in the lithosphere is large, and the effect of structures other than fracture zones such as Gorda Ridge is small in profile 4(b). The result is shown in Fig. 5.

The residual gravity anomaly is explained by the abrupt thickness difference at the fracture zone. When the difference between the vertical fault model and observed residual gravity anomaly is significant, the difference is explained by the structure shown by the dashed line.

\section{Geophysical Meaning of Difference of Thickness of Lithosphere}

According to the lithospheric thickening model presented by YosHII (1973), thickness of the lithosphere is proportional to the square root of its age. The relation applies well to the whole Pacific as a first approximation (TOMODA and FuJImoto, 1982).

As to the profile in Fig. 4(b), the age of the ocean basin given by magnetic lineations is $31 \mathrm{Ma}$. in the southern region and $3 \mathrm{Ma}$. in the northern region 

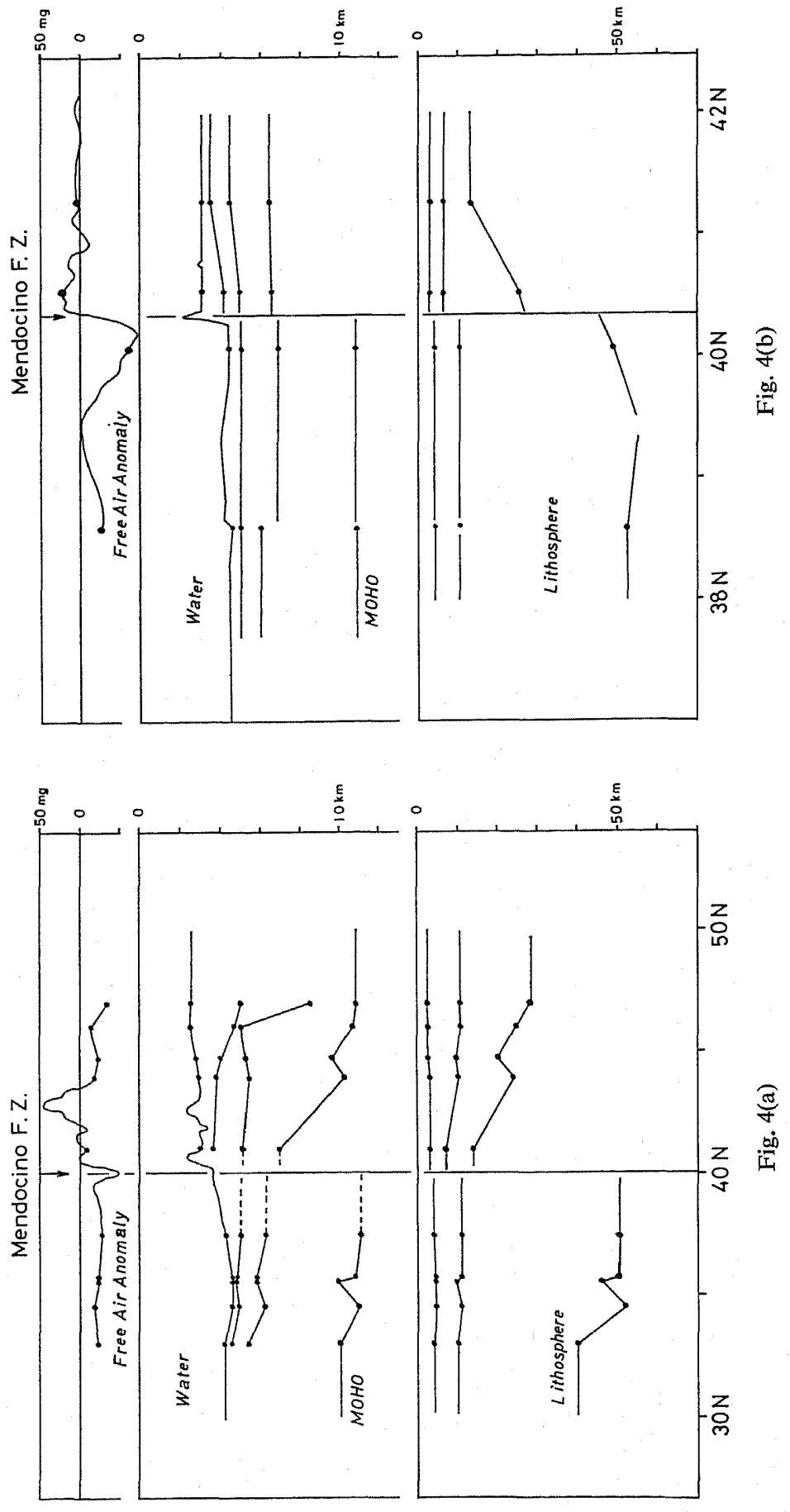


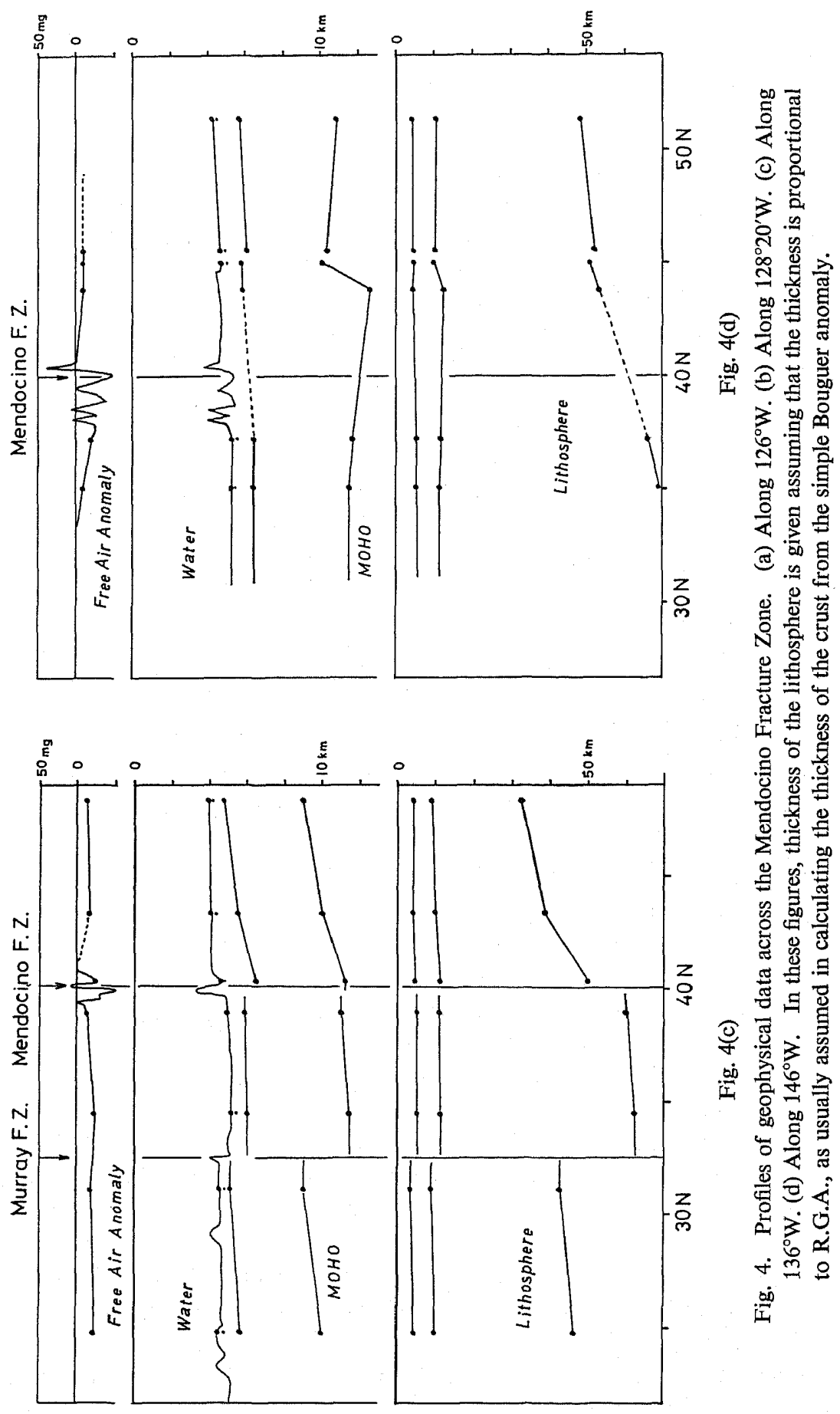




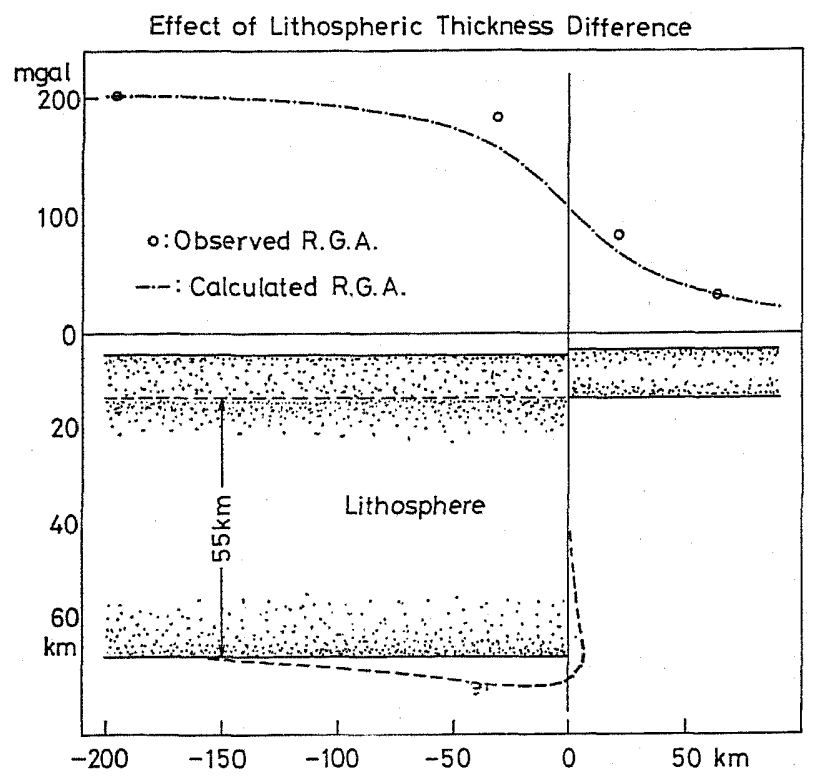

Fig. 5. Lithosphere thickness difference estimated two-dimensionally from observed residual gravity anomalies (R.G.A.) along the profile shown in Fig. 4(b). Calculated R.G.A. show the gravimetric effect of lithospheric thickness difference of $55 \mathrm{~km}$.

(Atwater and Menard, 1970). The difference of the thickness of lithosphere on both sides of the fracture zone is approximately explained by the difference in age.

What is expected with the difference in lithosphere thickness? Subduction would take place at the fracture zone.

One of the important forces derived from the thickness difference of the lithosphere is vertical force due to the buoyancy of the thinner lithosphere. Positive free air anomalies-mass excess in the north of the fracture zone-are interpreted as being supported by the buoyancy of the thin lithosphere. This means that the isostatic equilibrium is approximately achieved, not at the Moho, but at the bottom of the lithosphere.

Another important force derived from the thickness difference of the lithosphere is horizontal force. The process is similar to the meteorological phenomena where the motion of the atmosphere is produced by the lateral pressure difference.

The force in the slab pull model is roughly a product of the effective depth of the slab and its thickness, and the lateral driving force at the fracture zone is roughly square of the thickness difference of the lithosphere.

Another important force in the case of the vertical fault is the pressure gradient at the fault plane, which would result in penetration of high density 
material at the lower part of the thick lithosphere into the asthenosphere. This process would result in initiation of subduction at the fracture zone, though such structure is not so clearly seen in Fig. 5.

\section{Conclusion}

In this paper the authors proposed the possibility of the existence of horizontal driving force of the plate motion from the thickness difference of the lithosphere at the fracture zone. The situation resembles the oceanographic phenomenon which takes place when different water masses having different density meet. The authors suppose that the horizontal pressure difference may play an important role, as it does in oceanographic and meteorologic phenomena.

\section{REFERENCES}

Atwater, T. M. and H.W. Menard, Magnetic lineations in the northwestern Pacific, Earth Planet. Sci. Lett., 7, 445-450, 1970.

Dehlinger, P., R. W. Cough, and M. GemperLe, Gravity structure of the eastern part of the Mendocino escarpment, J. Geophys. Res., 72, 1233-1247, 1967.

Dehlinger, P., R. W. Cough, D. A. McManus, and M. Gemperle, Northeast Pacific structure, in The Sea, ed. A. E. Maxwell, Vol. 4, Part II, pp. 133-189, John Wiley \& Sons Inc., New York, 1970.

DETRICK, R. S., JR., An analysis of geoid anomalies across the Mendocino fracture zone: Implications for thermal models of the lithosphere, J. Geophys. Res., 86, 11751-11762, 1981.

SHOR, G. G., JR., P. DeHLINGER, H. K. KIRK, and W. S. FRENCH, Seismic refraction studies off Oregon and northern California, J. Geophys. Res., 73, 2175-2194, 1968.

Tomoda, Y. and H. Furmoto, Gravity anomalies in the western Pacific and geophysical interpretation of their origin, J. Phys. Earth, 29, 387-419, 1981.

Tomoda, Y. and H. Fusmoto, Residual gravity anomalies and their application to global dynamics, Proceedings of the General Meeting of the IAG., Tokyo, May 7-15, 1982, 238-242, 1982.

Tomoda, Y., H. Fujimoto, T. Matsumoto, and Y. Kono, Residual gravity anomalies of the Hawaiian seamounts and anomalies of the thickness of lithosphere, J. Seismol. Soc. Japan, Ser. II, 35, 293-301, 1982.

RaIT, R. W., Seismic refraction studies of the Mendocino fracture zone, Abstracts of Papers, Int. Assoc. Phys. Oceanogr., 13th General Assembly, Berkeley, 6, 71, 1963.

YosHII, T., Upper mantle structure beneath the north Pacific and the marginal seas, J. Phys. Earth, 21, 313-328, 1973. 